\title{
Credit Constraints and Self-Fulfulling Business Cycles
}

\author{
Zheng Liu \\ Federal Reserve Bank of San Francisco \\ Pengfei Wang \\ Hong Kong University of Science and Technology
}

September 2011

Working Paper 2010-22

http://www.frbsf.org/publications/economics/papers/2010/wp10-22bk.pdf

The views in this paper are solely the responsibility of the authors and should not be interpreted as reflecting the views of the Federal Reserve Bank of San Francisco or the Board of Governors of the Federal Reserve System. 


\title{
CREDIT CONSTRAINTS AND SELF-FULFILLING BUSINESS CYCLES
}

\author{
ZHENG LIU AND PENGFEI WANG
}

\begin{abstract}
We argue that credit constraints not just amplify fundamental shocks, they can also lead to self-fulfilling business cycles. To make this point, we study a model in which productive firms are credit constrained, with credit limits determined by equity value. A drop in equity value tightens credit constraints and reallocates resources from productive to unproductive firms. This reallocation reduces aggregate productivity and further depresses equity value and further tightens credit constraints, generating a financial multiplier that amplifies the effects of fundamental shocks. At the aggregate level, credit externality manifests as increasing returns and thus can lead to self-fulfilling business cycles.
\end{abstract}

\section{INTRODUCTION}

In the presence of credit constraints, financial factors can play an important role in macroeconomic fluctuations. For instance, if it is costly to enforce loan contracts or monitor project outcomes, then borrowing capacity will be limited by the value of the borrower's collateral assets or net worth. When credit constraints are binding, an increase in asset prices eases the constraints and thus helps expand production and investment. Expanded production and investment in turn raise the borrower's collateral value and net worth, further easing the constraints. This financial accelerator

Date: September 14, 2011.

Key words and phrases. Credit constraints, reallocation, financial multiplier, indeterminacy, aggregate productivity, business cycles.

JEL classification: D24, E32, E44.

For helpful comments and suggestions, we are grateful to John Fernald, Reuven Glick, Chad Jones, Nobu Kiyotaki, Kevin Lansing, Richard Rogerson, Mark Spiegel, and seminar participants at the Bank of France, the Federal Reserve Bank of San Francisco, the University of California at San Diego, the 2010 Tsinghua Workshop in Macroeconomics, and the 2011 Shanghai Macroeconomics Workshop, and the 2011 Far Eastern Meeting of the Econometric Society. An earlier draft of the paper was circulated under the title "Indeterminate Credit Cycles." The views expressed herein are those of the authors and do not necessarily reflect the views of the Federal Reserve Bank of San Francisco or the Federal Reserve System. Liu: Federal Reserve Bank of San Francisco; email: Zheng.Liu@sf.frb.org. Wang: Hong Kong University of Science and Technology; email: pfwang@ust.hk. 
can, in principle, amplify macroeconomic fluctuations by transforming small economic shocks into large business cycles (Kiyotaki and Moore, 1997; Bernanke, Gertler, and Gilchrist, 1999). Recent studies show that the financial accelerator is empirically important, especially for amplifying and propagating financial shocks (Christiano, Motto, and Rostagno, 2008; Liu, Wang, and Zha, 2011). The goal of this paper is to point out that credit constraints not only amplify fundamental shocks, but that sufficiently tight credit constraints can lead to self-fulfilling business cycles.

To make this point, we study a business cycle model with financial friction. The model features a representative household who consumes a homogeneous good and supplies labor to firms. The household invests the good to accumulate capital, which is rented to firms in a competitive market. Firms have access to a constant returns technology that transforms capital and labor into goods. In each period, firms draw an idiosyncratic productivity. If a firm chooses to produce, it needs to finance operating costs through external borrowing.

Limited contract enforcement gives rise to credit constraints. Under optimal contracts, credit and production are allocated to firms with productivity above a cut-off level. Incentive compatibility implies that the amount of loans available to operating firms is bounded above by a fraction of firms' expected equity value. Thus, in equilibrium, only productive firms operate and operating firms face binding credit constraints. Firms with productivity below the cut-off level remain idle.

The model generates a financial multiplier that amplifies macroeconomic shocks. Since borrowing capacity is bounded by firms' expected equity value, an increase in equity value enlarges the borrowing capacity for productive firms. With more credit available, productive firms are able to produce more by hiring more workers and renting more capital. The rise in factor prices crowds out less productive firms and, as a consequence, the cut-off level of productivity rises and resources are shifted to more productive firms. This reallocation raises aggregate productivity and leads to further increases in equity value and further expansion in credit, generating a ripple effect.

The reallocation effect stemming from credit constraints leads to procyclical aggregate productivity. In our model, measured total factor productivity (TFP) contains a financial factor, which corresponds to the cut-off level of productivity, which in turn is a monotonic function of aggregate leverage measured by the ratio of working capital loans to aggregate output. An increase in leverage raises firms' borrowing capacity and shifts resources to productive firms. Thus, aggregate productivity increases with 
leverage. In our model, working-capital leverage is procyclical because firms borrow to finance both working capital (i.e., variable costs) and a per-period fixed cost. In recessions when equity value drops, total available credit declines; but since the average fixed cost increases in recessions, the credit available to finance working capital declines by even more than does total credit. Thus, the ratio of working capital declines relative to output, leading to procylical leverage, as in the data. Procyclical leverage implies procyclical aggregate productivity. In this sense, financial friction provides an independent source of procyclical movements in aggregate productivity separate from changes in true technology. ${ }^{1}$

Since aggregate productivity is procyclical, any shock that raises aggregate capital and labor inputs would also raise aggregate output more than proportionately. This implies aggregate increasing returns. We show that aggregate dynamics in our model with credit constraints and constant returns technology at the firm level are isomorphic to those in a representative-agent economy with increasing returns technology. The degree of increasing returns in the aggregated version of our economy corresponds to the size of the financial multiplier. With sufficiently poor contract enforcement and thus sufficiently tight credit constraints, the model implies a sufficiently large financial multiplier and thus gives rise to the possibility of self-fulfilling, sunspot-driven business cycles.

The financial transmission mechanism in our model helps explain some empirical facts documented in the literature. For example, Ramey and Ramey (1995) document that countries with lower GDP growth experience higher growth volatility. Our model's predictions are consistent with this evidence. In our model, poorer contract enforcement implies tighter credit constraints, which lead to greater misallocation and thus lower levels of aggregate productivity and output. Poorer contract enforcement also leads to greater volatility of aggregate output because it implies a larger financial multiplier that amplifies fundamental shocks and, with sufficiently tight credit constraints, it may also lead to sunspot-driven business cycle fluctuations.

It is well-known in the literature that resource misallocation can lower a country's TFP (Rustuccia and Rogerson, 2008; Hsieh and Klenow, 2009; Fernald and Neiman, 2010). For example, Hsieh and Klenow (2009) show that misallocation is quantitatively important for China and India, and reallocation can potentially improve TFP

\footnotetext{
${ }^{1}$ The importance of resource reallocation for understanding the procyclical behavior of aggregate productivity has been noted by Basu and Fernald (1997, 2001). Our model emphasizes a specific mechanism of reallocation through credit constraints.
} 
by $30-50 \%$ in these countries. Our theory suggests that misallocation may have a financial origin. In a country with poor financial development (such as China), credit constraints can lead to misallocation between heterogeneous firms and thus depress the levels of TFP. Improvement in financial institutions in such a country would help reallocate resources to more productive firms and lead to potentially large improvement in the country's TFP and income levels.

The rest of the paper is organized as follows. Section II discusses the contributions of our paper in relation to the literature. Section III presents the baseline model with financial friction and characterizes optimal financial contracts. Section IV illustrates the financial multiplier and the relation between financial factors and aggregate TFP. Section V shows the connections between firm-level financial friction and aggregate increasing returns and discusses the possibility of self-fulfilling business cycles. Section VI concludes. The Appendices contain some detailed derivations and proofs.

\section{Related Literature}

Our work builds on a large strand of literature that examines the possibility of indeterminate equilibria in RBC models. In an influential study, Benhabib and Farmer (1994) first point out that a standard one-sector RBC model with increasing returns to scale can generate indeterminacy. Farmer and Guo (1994) show that, in such an economy, sunspot shocks are quantitatively important for business cycles. The degree of increasing returns required to generate indeterminacy in this class of models, however, is considered too large to be consistent with empirical evidence (Basu and Fernald, 1995, 1997). Subsequent contributions by Benhabib and Farmer (1996) and Benhabib and Nishmura (1998) show that, in multisector RBC models, the required externality to generate indeterminacy is substantially smaller. Wen (1998) extends the one-sector model in Benhabib and Farmer (1994) by introducing variable capacity utilization and shows that the model can generate indeterminacy with empirically plausible increasing returns. Benhabib and Wen (2004) study a version of the Wen (1998) model and find that, under parameter configurations that allow for indeterminacy, the RBC model driven by demand shocks performs well in matching the business cycle facts along several important dimensions. Schmitt-Grohe (1997) com-

pares four different models and finds that models with countercyclical markups rely on a lower degree of increasing returns to generate indeterminacy than those with constant markups. Galí (1994) and Wang and Wen (2008) show that variations in 
the composition of aggregate demand help generate countercyclical markups and indeterminacy. Jaimovich (2007) shows that a model with endogenous entry and exit of firms and thus countercyclical markups can generate indeterminacy even without increasing returns. ${ }^{2}$

Our model does not rely on increasing returns to generate indeterminacy. Instead, we focus on the role of financial friction and, in particular, the reallocation effect of credit constraints in amplifying fundamental shocks and generating expectationsdriven equilibria. In our model, productive firms face binding credit constraints and only those with productivity above a cutoff level choose to produce. Operating firms earn economic profits since their productivity levels are higher than the cutoff level. In a business cycle boom, credit constraints are eased and resources are concentrated in high-productivity firms. Accordingly, the cutoff level of productivity rises and aggregate economic profit falls. Thus, our model generates countercyclical markups and indeterminacy through financial friction, which is a different source of indeterminacy than those considered in the previous literature.

Our focus on financial friction is similar to Woodford (1986), who first recognizes the possibility that borrowing constraints help generate stationary sunspot equilibria. Woodford (1986) considers an economy with two classes of representative agents and with no heterogeneity within each class. Thus, the Woodford model does not generate the reallocation effect of credit constraints which, as we show, is a central ingredient in our model's amplification mechanism and crucial for generating indeterminacy.

Our paper contributes to the rapidly growing literature on the role of financial friction for macroeconomic fluctuations. A comprehensive survey of that literature is beyond the scope our paper. ${ }^{3}$ The credit amplification mechanism in our model is closely related to the financial accelerator studied by Carlstrom and Fuerst (1997), Bernanke, Gertler, and Gilchrist (1999), and Kiyotaki and Moore (1997, 2008), Jermann and Quadrini (Forthcoming), among others. We follow Kiyotaki and Moore (1997, 2008) and Jermann and Quadrini (Forthcoming) and focus on limited contract enforcement problems. We generalize these models in the literature by introducing firm-level heterogeneity, which helps simplify solution methods for this class of models. Since it is difficult to solve a model with occasionally binding credit constraints,

\footnotetext{
${ }^{2}$ The indeterminacy in this class of business cycle models are dynamic examples of the sunspot equilibria initially studied by Azariadis (1981) and Cass and Shell (1983). See Benhabib and Farmer (1999) for a comprehensive survey of the literature.

${ }^{3}$ For surveys of the literature on financial friction in DSGE models, see Bernanke, Gertler, and Gilchrist (1999) and Gertler and Kiyotaki (2009).
} 
existing literature typically follows Kiyotaki and Moore (1997) and assumes that borrowers are less patient than lenders so that credit constraints are binding in the steady state equilibrium (and also around the steady state). In our model, credit constraints are binding only for productive firms. In the aggregated economy, credit friction is summarized by the cut-off level productivity that depends only on aggregate economic conditions. Thus, when we solve for aggregate dynamics, we do not need to deal with occasionally binding constraints.

\section{THE MODEL}

The model economy is populated by two types of agents - a representative household and a representative entrepreneur - both infinitely lived. There are three types of commodities traded in the economy in perfectly competitive markets: goods, labor, and loanable funds. The household consumes and invests the goods and supplies labor and capital to the entrepreneur. The entrepreneur family has a large number of managers, each managing a firm with a constant returns technology that transforms labor and capital into consumption goods. To incorporate financial friction, we assume that firms face idiosyncratic productivity shocks and, if it is profitable to produce, active firms finance operation costs by borrowing from a competitive financial intermediary. Contract enforcement is costly. Thus, operating firms face credit constraints.

\section{III.1. The representative household and the representative entrepreneur.} The representative household has the utility function

$$
\mathrm{E} \sum_{t=0}^{\infty} \beta^{t}\left\{\ln C_{t}^{h}-a_{L} \frac{N_{t}^{1+\chi}}{1+\chi}\right\}
$$

where $\beta \in(0,1)$ denotes the household's subjective discount factor, $C_{t}^{h}$ denotes the household's consumption, $N_{t}$ denotes the hours worked, $a_{L}>0$ is the utility weight for leisure, $\chi>0$ is the inverse Frish elasticity of labor supply, and E is the expectation operator.

The household chooses consumption $C_{t}^{h}$, labor supply $N_{t}$, and new capital stock $K_{t+1}^{h}$ to maximize the utility (1) subject to the sequence of budget constraints

$$
C_{t}^{h}+K_{t+1}^{h} \leq w_{t} N_{t}+\left(1+r_{t}-\delta\right) K_{t}^{h} \quad \forall t \geq 0
$$

and the non-negativity constraints $C_{t}^{h} \geq 0$ and $K_{t+1}^{h} \geq 0$, taking as given the labor wage rate $w_{t}$ and the capital rental rate $r_{t}$. The parameter $\delta \in(0,1)$ denotes the capital depreciation rate. 
The representative entrepreneur has the utility function

$$
\mathrm{E} \sum_{t=0}^{\infty} \tilde{\beta}^{t} \ln C_{t}^{e},
$$

where $\tilde{\beta} \in(0,1)$ denotes the entrepreneur's subjective discount factor and $C_{t}^{e}$ denotes the entrepreneur's consumption.

The entrepreneur chooses consumption $C_{t}^{e}$ and new capital stock $K_{t+1}^{e}$ to maximize (3) subject to the sequence of budget constraints

$$
C_{t}^{e}+K_{t+1}^{e} \leq\left(1+r_{t}-\delta\right) K_{t}^{e}+D_{t}, \quad \forall t \geq 0,
$$

along with the non-negative constraints $C_{t}^{e} \geq 0$ and $K_{t+1}^{e} \geq 0$, taking as given the rental rate $r_{t}$. In the budget constraint, the term $D_{t}$ denotes the dividend payments received from the firms that the entrepreneur owns.

We assume that the entrepreneur is less patient than the household (i.e., $\tilde{\beta}<\beta$ ). In equilibrium, the household is the only saver and the entrepreneur does not hold any capital (i.e., $K_{t+1}^{e}=0$ for all $t \geq 0$ ). Thus, the entrepreneur's consumption equals dividend payments from firms. ${ }^{4}$

III.2. The firms. The entrepreneur owns a large number of firms. Each firm has access to a constant returns technology that transforms capital and labor into goods. In each period, each firm faces an aggregate technology shock $A_{t}$ and draws an idiosyncratic productivity $\omega$ from the distribution $F(\omega)$. Without loss of generality, we index firms by their productivity draws $\omega$.

The production function for firm $\omega$ is given by

$$
y_{t}(\omega)=\omega A_{t} k_{t}(\omega)^{\alpha} n_{t}(\omega)^{1-\alpha}
$$

where $y_{t}(\omega)$ denotes output, $k_{t}(\omega)$ and $n_{t}(\omega)$ denote capital and labor inputs, and $\alpha \in(0,1)$ denotes the elasticity of output with respect to capital input.

Aggregate technology shock $A_{t}$ follows the stationary stochastic process

$$
\ln A_{t}=\left(1-\rho_{a}\right) \ln A+\rho_{a} \ln A_{t-1}+\varepsilon_{a t},
$$

where $\rho_{a} \in(0,1)$ measures the persistence of the aggregate technology shock and $\varepsilon_{a t}$ is an i.i.d. normal process with a mean of zero and a variance of $\sigma_{a}^{2}{ }^{5}$

\footnotetext{
${ }^{4}$ The assumption that the representative entrepreneur is less patient than the representative household helps simplify the analysis. The derivations of firm-level credit constraints below do not rely on this assumption.

${ }^{5}$ The shock process can be easily generalized to allow for trend growth without affecting the model's business cycle dynamics.
} 
To make analytical aggregation feasible, we follow Carlstrom and Fuerst (1997) and Bernanke, Gertler, and Gilchrist (1999) by assuming that the idiosyncratic productivity shock $\omega$ is i.i.d. across time and across firms. Further, we assume that $\omega$ is drawn from a Pareto distribution defined over the interval $[1, \infty)$, with the distribution function

$$
F(\omega)=1-\omega^{-\sigma}
$$

where $\sigma>1$ is the shape parameter, which determines the dispersion of the distribution.

III.3. Financial contracts. In each period, firms need to pay a fixed cost $\phi$ to stay in business. We interpret the fixed cost as a cost of accessing credit market, which covers the cost of financial intermediation. Firms need to borrow from a competitive financial intermediary to finance payments of the fixed cost and variable costs. Following Jermann and Quadrini (Forthcoming), we assume that there is a mismatch of cash flows so that these payments need to be made in the beginning of the period, before production takes place. Loans are repaid at the end of the period after production completes.

Denote by $l_{t}(\omega)$ the amount of loans that a firm with productivity $\omega$ can borrow and by $V_{t}(\omega)$ the firm's value. Define $V_{t} \equiv \int V_{t}(\omega) f(\omega) d \omega$ as the ex ante value of the firm (with idiosyncratic productivity integrated out). The firm solves the valuemaximizing problem

$$
V_{t}(\omega)=\max _{n_{t}(\omega), k_{t}(\omega)} \omega A_{t} k_{t}(\omega)^{\alpha} n_{t}(\omega)^{1-\alpha}-w_{t} n_{t}(\omega)-r_{t} k_{t}(\omega)-\phi+\mathrm{E}_{t} \tilde{\beta} \frac{\Lambda_{t+1}^{e}}{\Lambda_{t}^{e}} V_{t+1}
$$

subject to the borrowing constraint

$$
w_{t} n_{t}(\omega)+r_{t} k_{t}(\omega)+\phi \leq l_{t}(\omega)
$$

and an incentive constraint to be specified below. The term $\Lambda_{t}^{e}$ denotes the marginal utility of the entrepreneur who owns all firms.

Since contract enforcement is imperfect, borrowers have an incentive to default on a loan. Optimal contracts solves the firm's problem subject to an incentive constraint, so that no default occurs in equilibrium. We now specify the incentive constraints.

If a firm with the productivity draw $\omega$ does not default at the end of the period, it repays the loan $l_{t}(\omega)$, keeps its revenue $\omega A_{t} k_{t}(\omega)^{\alpha} n_{t}(\omega)^{1-\alpha}$ and any unspent loans $l_{t}(\omega)-w_{t} n_{t}(\omega)-r_{t} k_{t}(\omega)-\phi$ after payments of operating costs. The non-default value 
for the firm is thus given by

$$
\begin{aligned}
V_{t}^{N}(\omega)= & \omega A_{t} k_{t}(\omega)^{\alpha} n_{t}(\omega)^{1-\alpha}+\left[l_{t}(\omega)-w_{t} n_{t}(\omega)-r_{t} k_{t}(\omega)-\phi\right] \\
& -l_{t}(\omega)+\tilde{\beta} E_{t} \frac{\Lambda_{t+1}^{e}}{\Lambda_{t}^{e}} V_{t+1} .
\end{aligned}
$$

If the firm does not pay back the loan at the end of the period (i.e., if the firm defaults), we follow Jermann and Quadrini (Forthcoming) and assume that the lender can recover a fraction $\theta$ of the firm's expected equity value. In this sense, the parameter $\theta$ captures the strength of contract enforcement. The value of default is given by

$$
\begin{aligned}
V_{t}^{D}(\omega)= & \omega A_{t} k_{t}(\omega)^{\alpha} n_{t}(\omega)^{1-\alpha}+\left[l_{t}(\omega)-w_{t} n_{t}(\omega)-r_{t} k_{t}(\omega)-\phi\right] \\
& +\tilde{\beta}(1-\theta) E_{t} \frac{\Lambda_{t+1}^{e}}{\Lambda_{t}^{e}} V_{t+1} .
\end{aligned}
$$

The firm chooses not to default if and only if $V_{t}^{D}(\omega) \leq V_{t}^{N}(\omega)$. In light of the value functions in (10) and (12), the incentive constraint can be rewritten as

$$
l_{t}(\omega) \leq \tilde{\beta} \theta E_{t} \frac{\Lambda_{t+1}^{e}}{\Lambda_{t}^{e}} V_{t+1} .
$$

III.4. Allocations of credit and production. We now examine the allocations of credit and production across firms with different productivity. For this purpose, we make the distinction between working capital, which corresponds to the variable factor payments, and the overall cost, which includes also the fixed cost. Define $b_{t}(\omega)=w_{t} n_{t}(\omega)+r_{t} k_{t}(\omega)$ as the working capital. The incentive constraint (13) can then be rewritten as

$$
b(\omega) \leq \tilde{\beta} \theta E_{t} \frac{\Lambda_{t+1}^{e}}{\Lambda_{t}^{e}} V_{t+1}-\phi \equiv b_{t},
$$

where we have used the borrowing constraint (9) to replace $l(\omega)$. The variable $b_{t}$ denotes the credit limit for working capital loans.

To obtain the variable cost function, the firm chooses variable input factors $n_{t}(\omega)$ and $k_{t}(\omega)$ to minimize $w_{t} n_{t}(\omega)+r_{t} k_{t}(\omega)$ subject to the constraint $\omega A_{t} k_{t}^{\alpha}(\omega) n_{t}^{1-\alpha}(\omega) \geq$ $y$. The variable cost function is given by $C(y, \omega)=y \frac{\omega_{t}^{*}}{\omega}$, where

$$
\omega_{t}^{*} \equiv \frac{1}{A_{t}}\left(\frac{w_{t}}{1-\alpha}\right)^{1-\alpha}\left(\frac{r_{t}}{\alpha}\right)^{\alpha} .
$$

The incentive constraint (14) implies that the total variable cost (which needs to be financed through working capital loans) cannot exceed $b_{t}$. In particular, we have

$$
C\left(y_{t}(\omega), \omega\right)=y_{t}(\omega) \frac{\omega_{t}^{*}}{\omega} \leq b_{t}
$$


Optimal contracts maximize the firm's value subject to the firm's borrowing constraint and the incentive constraint. Formally, the optimal contract problem is to choose $y_{t}(\omega)$ to maximize

$$
y_{t}(\omega)-y_{t}(\omega) \frac{\omega_{t}^{*}}{\omega}-\phi+\tilde{\beta} E_{t} \frac{\Lambda_{t+1}^{e}}{\Lambda_{t}^{e}} V_{t+1}
$$

subject to the constraints

$$
\begin{aligned}
y_{t}(\omega) \frac{\omega_{t}^{*}}{\omega} & \leq b_{t}, \\
y_{t}(\omega) & \geq 0, .
\end{aligned}
$$

Solving the optimal contract problem gives the allocations of production and credit, as we summarize in the following proposition:

Proposition 1 . There exists a cut-off level of productivity $\omega_{t}^{*} \in[1, \infty)$ such that the production allocation is given by

$$
y_{t}(\omega)=\left\{\begin{array}{cc}
\frac{b_{t} \omega}{\omega_{t}^{*}}, & \text { if } \omega \geq \omega_{t}^{*} \\
0, & \text { otherwise }
\end{array}\right.
$$

and the working-capital credit allocation is given by

$$
b_{t}(\omega)=\left\{\begin{array}{cc}
b_{t}, & \text { if } \omega \geq \omega_{\mathrm{t}}^{*} \\
0 & \text { otherwise }
\end{array}\right.
$$

The credit limit for working capital financing $b_{t}$ and the cut-off productivity $\omega_{t}^{*}$ are defined in (14) and (15), respectively.

Proposition 1 shows that firms with sufficiently high levels of productivity choose to operate and less productive firms remain inactive. For the marginal firm with productivity $\omega_{t}^{*}$, total revenue equals total variable cost. Equation (17) shows that the marginal firm has an operating loss that equals the fixed cost. The firm chooses to stay in business because it expects to obtain positive equity value in future periods.

Under optimal contracts, productive firms are credit-constrained, and the credit limit for working capital financing is given by a fraction $\theta$ of the firms' expected equity value net of payments for fixed costs. Unproductive firms stay inactive and they do not borrow. The parameter $\theta$ captures the strength or effectiveness of contract enforcement. Stronger contract enforcement implies a higher credit limit. A higher fixed cost for accessing credit markets lowers the available credit for productive firms' working-capital financing and thus tightens the credit constraints. 
III.5. Competitive equilibrium and aggregation. A competitive equilibrium consists of sequences of prices $\left\{w_{t}, r_{t}\right\}$, allocations for the household $\left\{C_{t}^{h}, K_{t+1}^{h}, N_{t}\right\}$, allocations for the entrepreneur $\left\{C_{t}^{e}, K_{t+1}^{e}\right\}$, allocations for firms $\left\{k_{t}(\omega), n_{t}(\omega), b_{t}(\omega)\right\}$ such that, taking the prices as given, the allocations for each type of agents solve their optimizing problems and all markets clear.

Factor market clearing implies that

$$
\int k_{t}(\omega) d F(\omega)=K_{t}^{h}+K_{t}^{e}=K_{t}, \quad \int n_{t}(\omega) d F(\omega)=N_{t}
$$

Loan market clearing implies that

$$
\int b_{t}(\omega) d F(\omega)=w_{t} N_{t}+r_{t} K_{t}
$$

where we have imposed the equilibrium condition that $K_{t+1}^{e}=0$ since the entrepreneur is less patient than the household.

Goods market clearing implies that

$$
C_{t}^{h}+C_{t}^{e}+K_{t+1}=(1-\delta) K_{t}+Y_{t}-\phi
$$

where $Y_{t}=\int y_{t}(\omega) d F(\omega)$ denotes aggregate output.

Integrating the production allocation in equation (20) across firms, we obtain aggregate output given by

$$
Y_{t}=\int_{\omega \geq \omega_{t}^{*}} \frac{b_{t}}{\omega_{t}^{*}} \omega d F(\omega)=\frac{\sigma}{\sigma-1} b_{t} \omega_{t}^{*-\sigma} .
$$

With constant returns technology and perfect mobility of factors, the capital-labor ratio is independent of firms' idiosyncratic productivity. In particular, cost-minimizing implies that

$$
\frac{w_{t}}{r_{t}}=\frac{1-\alpha}{\alpha} \frac{k_{t}(\omega)}{n_{t}(\omega)}=\frac{1-\alpha}{\alpha} \frac{K_{t}}{N_{t}}
$$

Cost minimizing also implies that aggregate payments to input factors are given by

$$
w_{t} N_{t}+r_{t} K_{t}=\omega_{t}^{*} A_{t} K_{t}^{\alpha} N_{t}^{1-\alpha}
$$

As the capital-labor ratio for each firm is identical, integrating the production function (5) across firms implies that

$$
A_{t} K_{t}^{\alpha} N_{t}^{1-\alpha}=\int \frac{y_{t}(\omega)}{\omega} d F(\omega)=\int_{\omega \geq \omega_{t}^{*}} \frac{b_{t}}{\omega_{t}^{*}} d F(\omega)=b_{t} \omega_{t}^{*-\sigma-1},
$$

where the second equality follows from the production allocation (20) and the final equality from the Pareto distribution function. 
Combining (25) and (28), we obtain the aggregate production function

$$
Y_{t}=\frac{\sigma}{\sigma-1} \omega_{t}^{*} A_{t} K_{t}^{\alpha} N_{t}^{1-\alpha}
$$

\section{CRedit CONStraints And AGgregate Productivity}

Since productive firms face binding credit constraints and cannot operate at full capacity, the presence of credit constraints leads to misallocation and depressed total factor productivity (TFP). We now draw a formal connection between credit constraints and aggregate productivity in our model. We further show that, in the presence of fixed cost for financial intermediation, credit constraints help amplify macroeconomic fluctuations through reallocation of resources.

IV.1. Credit constraints and misallocation. The aggregate production function (29) reveals that measured TFP is given by

$$
T F P_{t} \equiv \frac{Y_{t}}{K_{t}^{\alpha} N_{t}^{1-\alpha}}=\frac{\sigma}{\sigma-1} \omega_{t}^{*} A_{t}
$$

Thus, measured TFP reflects true technology changes $\left(A_{t}\right)$ and endogenous variations in the cutoff level of productivity $\left(\omega_{t}^{*}\right)$ that determines which firms are active.

Absent credit constraints, the only firms that operate would be those with the highest productivity draw $\omega^{\max }{ }^{6}$ In the presence of credit constraints, however, less productive firms (i.e., those with productivity between $\omega_{t}^{*}$ and $\omega^{\max }$ ) are able to survive. In this sense, credit constraints create misallocation of resources, the magnitude of which is captured by the cutoff level of productivity $\omega_{t}^{*}$.

The following proposition establishes the relation between the endogenous component of TFP (the misallocation effect) and the average tightness of credit constraints.

Proposition IV.1. There is a one-to-one and monotonic mapping between $\omega_{t}^{*}$ and aggregate loan-to-output ratio. In particular,

$$
\omega_{t}^{*}=\left[\frac{b_{t}}{Y_{t}} \frac{\sigma}{\sigma-1}\right]^{1 / \sigma} .
$$

The loan-to-output ratio in turn depends on the tightness of the credit constraints:

$$
\frac{b_{t}}{Y_{t}}=\frac{\tilde{\beta} \theta}{1-\tilde{\beta}}\left[\frac{1}{\sigma}-\bar{\phi}_{t}\right]-\bar{\phi}_{t},
$$

where $\bar{\phi}_{t} \equiv \phi / Y_{t}$.

\footnotetext{
${ }^{6}$ Strictly speaking, the notion of the "most productive firms" is a limiting concept since the support of the Pareto distribution is not bounded from above (i.e., with $\omega^{\text {max }}$ approaching infinity).
} 
Proof. The equality in (31) follows immediately from (25). To obtain the relation in (32), we first note that (14) implies that the working-capital credit limit $b_{t}$ is determined by expected future equity value. The equity value $V_{t}$ can be solved out from the recursive relation $V_{t}=C_{t}^{e}+\tilde{\beta} \mathrm{E}_{t} \frac{C_{t}^{e}}{C_{t+1}^{e}} V_{t+1}$, which yields

$$
V_{t}=\frac{1}{1-\tilde{\beta}} C_{t}^{e}
$$

In equilibrium, $C_{t}^{e}$ is the aggregate dividend payments from all firms, which is given by

$$
C_{t}^{e}=Y_{t}-w_{t} N_{t}-r_{t} K_{t}-\phi=\frac{1}{\sigma} Y_{t}-\phi
$$

where the last equality follows from (27) and (29). We then have the credit limit

$$
b_{t}=\tilde{\beta} \theta E_{t} \frac{C_{t}^{e}}{C_{t+1}^{e}} V_{t+1}-\phi=\frac{\tilde{\beta} \theta}{1-\tilde{\beta}}\left[\frac{1}{\sigma} Y_{t}-\phi\right]-\phi,
$$

where the second equality uses (33) to substitute out $V_{t+1}$ and (34) to substitute out $C_{t}^{e}$. Dividing (35) through by $Y_{t}$, we obtain the desired equality in (32).

Proposition IV.1 implies that more credit would be available for productive firms if contract enforcement is stronger (i.e., $\theta$ is larger) or costs of financial intermediation are lower (i.e., $\phi / Y_{t}$ is smaller). With more available credit, resources are more concentrated in high-productivity firms, so the economy should have a higher level of TFP (see (31)). Empirical studies suggest that misallocation accounts for a large fraction of cross-country differences in TFP (Hsieh and Klenow, 2009). Our theory suggests that financial friction can be a source of misallocation that depresses TFP.

IV.2. Amplification through reallocation. Credit constraints not only lead to misallocation that depresses steady-state TFP, they also amplify technology shocks through reallocation of resources between firms with different levels of productivity. The following proposition establishes the conditions under which a financial multiplier arises.

Proposition IV.2. Holding input factors constant, a 1 percent change in technology shock leads to $\mu>1$ percent change in aggregate output, where $\mu$ is given by

$$
\mu \equiv \frac{d \log Y_{t}}{d \log A_{t}}=\frac{\sigma}{\sigma+1-\xi}, \quad \xi \equiv\left[1-\bar{\phi} \sigma \frac{1-\tilde{\beta}(1-\theta)}{\tilde{\beta} \theta}\right]^{-1}>1,
$$

where $\bar{\phi}=\phi / Y$ measures the steady-state cost of financial intermediation as a fraction of $G D P$. 
Proof. Substituting for $\omega_{t}^{*}$ in (29) by the relations in (31) and (32) and rearranging terms, we obtain

$$
Y_{t}^{1+\sigma}=\left(\frac{\sigma}{\sigma-1}\right)^{1+\sigma} \frac{\tilde{\beta} \theta}{1-\tilde{\beta}}\left[\frac{1}{\sigma} Y_{t}-\phi \frac{1-\tilde{\beta}(1-\theta)}{\tilde{\beta} \theta}\right]\left[A_{t} K_{t}^{\alpha} N_{t}^{1-\alpha}\right]^{\sigma} .
$$

Taking logarithms on both sides and applying total differentiation, we obtain (36).

Proposition IV.2 shows that tighter credit constraints lead to greater amplification of technology shocks. In particular, weaker contract enforcement (a smaller $\theta$ ) or more costly financial intermediation (a larger $\bar{\phi}$ ) leads to a greater financial multiplier (a larger $\mu$ ). The fixed cost of credit market access is crucial for reallocation because it hurts less-productive firms more. Indeed, the financial multiplier relies on the existence of the fixed cost. In the extreme case with $\phi=0$, we have $\mu=1$ and we obtain no financial multiplier $(\mu=1)$. In general, a positive value of $\phi$ gives rise to a positive financial multiplier $(\mu>1)$ and allows the strength of contract enforcement $(\theta)$ to play a role in the credit amplification mechanism.

To understand how the credit amplification mechanism works, consider a positive technology shock. On impact, output rises, which raises firms' equity value and, under the optimal contract, the credit line rises (see (35)). Equation (32) reveals that, in the presence of the fixed cost, the credit limit rises more than proportionately than does aggregate output because the boom in output reduces the average cost of financial intermediation measured by $\bar{\phi}$. Since firms with high levels of productivity choose to produce and active firms face binding working capital constraints (Proposition 1), the increased credit limit enables productive firms to expand production. Some less-productive firms are crowded out and become inactive. As a consequence, the cutoff level of productivity shifts up as the loan-to-output ratio rises (see equation (31)), which raises measured TFP (equation (30)) and thereby reinforcing the initial technology shock. Following a negative technology shock, the same logic applies with the direction reversed. The interactions between equity value and credit limits create a reallocation effect under credit constraints, which can amplify macroeconomic fluctuations.

\section{Aggregate Increasing Returns and Indeterminacy}

The reallocation effect represents a form of credit externality that stems from credit constraints. In an unconstrained economy, resources are concentrated in the most productive firms and changes in equity value do not have any impact on production allocation. In the presence of credit constraints, however, firms need to finance their 
working capital through borrowing and their borrowing capacity is limited by equity value. Thus, changes in equity value directly alter the borrowing capacity of the credit-constrained firms and lead to reallocation.

We have established that the reallocation effect of credit constraints is crucial in amplifying business cycle shocks. We now show that credit constraints at the firm level are equivalent to increasing returns at the aggregate level, despite that all firms operate a constant returns technology. Further, we show that the reallocation effect makes the economy prone to indeterminate equilibria and sunspot driven fluctuations, just like a representative-agent economy with increasing returns technology studied by Benhabib and Farmer (1994) and others.

V.1. Credit constraints and aggregate increasing returns. To see that aggregate technology in the model exhibits increasing returns, we log-linearize the reducedform aggregate production function (37) around the (unique) deterministic steady state to get

$$
\hat{y}_{t}=\mu\left[\hat{a}_{t}+\alpha \hat{k}_{t}+(1-\alpha) \hat{n}_{t}\right],
$$

where a hatted variable denotes the log-deviations of the corresponding variable from its steady-state value (e.g., $\hat{y}_{t} \equiv \log \left(Y_{t} / Y\right)$, where $Y$ is the steady-state level of output). The term $\mu$ is the financial multiplier given by (36). Equation (38) shows that $\mu$ also measures aggregate returns to scale. Thus, the reduced-form aggregate technology exhibits increasing returns if and only if there is a positive financial multiplier (i.e., $\mu>1$ ).

V.2. Theoretical possibility of self-fulfilling equilibria. It is well known that an economy with increasing returns can be prone to self-fulfilling, sunspot driven business cycles (Benhabib and Farmer, 1994). Since credit constraints in our model are observationally equivalent to aggregate increasing returns, we now examine the conditions under which sunspot-driven fluctuations can occur. To help exposition, we examine a continuous-time version of our model at the aggregate level and we abstract from aggregate shocks.

Define $X_{t} \equiv \frac{\sigma-1}{\sigma} Y_{t}$. Substituting this expression in equation (37), we obtain

$$
X_{t}=\left[\frac{\tilde{\beta} \theta}{1-\tilde{\beta}}\left(\frac{1}{\sigma-1} X_{t}-\tilde{\phi}\right)\right]^{\frac{1}{\sigma+1}}\left(A_{t} K_{t}^{\alpha} N_{t}^{1-\alpha}\right)^{\frac{\sigma}{\sigma+1}}
$$

where

$$
\tilde{\phi} \equiv \phi \frac{1-\tilde{\beta}(1-\theta)}{\tilde{\beta} \theta}
$$


The aggregate resource constraint in the continuous-time version of our model is given by

$$
\frac{\dot{K}_{t}}{K_{t}}=-\delta+\frac{X_{t}}{K_{t}}-\frac{C_{t}^{h}}{K_{t}}
$$

where we have substituted for $C_{t}^{e}$ in equation (24) by using (34) and we have imposed the equilibrium condition that $K_{t+1}^{e}=0$.

The intertemporal Euler equation for the household implies that

$$
\frac{\dot{C}_{t}^{h}}{C_{t}^{h}}=\alpha \frac{X_{t}}{K_{t}}-\delta-\rho,
$$

where $\rho \equiv-\log \beta$ is the subjective discount factor in the continuous-time model.

The household's labor supply decision is given by

$$
a_{L} N_{t}^{\chi} C_{t}^{h}=(1-\alpha) \frac{X_{t}}{N_{t}} .
$$

Equations (39) to (43), along with the transversality condition $\lim _{t \rightarrow \infty} e^{-\rho t} K_{t} / C_{t}^{h}=$ 0 and the initial condition $K_{0}=\bar{K}$ fully characterize the aggregate dynamics in our model with heterogeneous firms operating a constant returns technology and facing credit constraints.

The next proposition establishes an equivalence result between the aggregate dynamics in our model and those in the Benhabib and Farmer (1994) economy.

Proposition V.1. Aggregate dynamics in a continuous-time version of our model are identical, up to a first-order approximation, to those in the Benhabib and Farmer (1994, BF) economy where the social planner solves the problem

$$
\operatorname{Max} \quad U=\int e^{-\rho t}\left[\log C_{t}-a_{L} \frac{N_{t}^{1+\chi}}{1+\chi}\right]
$$

subject to

$$
C_{t}+\dot{K}_{t}=K_{t}^{\alpha} N_{t}^{1-\alpha}\left(\bar{K}_{t}^{\alpha} \bar{N}_{t}^{1-\alpha}\right)^{\mu-1}-\delta K_{t}
$$

where $\bar{K}$ and $\bar{N}$ represent average economy-wide levels of capital and labor.

Proof. The first-order necessary conditions in the BF model are given by

$$
\begin{aligned}
\frac{\dot{C}_{t}}{C_{t}} & =\alpha \frac{X_{t}}{K_{t}}-\delta-\rho, \\
a_{L} N_{t}^{\chi} C_{t} & =(1-\alpha) \frac{X_{t}}{N_{t}} \\
\frac{\dot{K}_{t}}{K_{t}} & =\frac{X_{t}}{K_{t}}-\delta-\frac{C_{t}}{K_{t}}, \\
X_{t} & =K_{t}^{\alpha \mu} N_{t}^{(1-\alpha) \mu}
\end{aligned}
$$


where $X_{t}$ denotes aggregate output. Equation (46) comes from the optimal consumptionsaving decision, (47) describes the optimizing labor-leisure choice, (48) rewrites the resource constraint (45), and (49) is the production function, where we have imposed the equilibrium conditions that $\bar{K}_{t}=K_{t}$ and $\bar{N}_{t}=N_{t}$. Since the utility function is strictly concave, these are also sufficient conditions for the optimizing problem in the BF model.

Log-linearizing equations (46) to (49) around the deterministic steady state, we obtain the following system of equations that characterizes equilibrium dynamics in the BF model:

$$
\begin{aligned}
\dot{c}_{t} & =(\delta+\rho)\left[x_{t}-k_{t}\right] \\
(1+\chi) n_{t} & =x_{t}-c_{t}, \\
\dot{k}_{t} & =\frac{\delta+\rho}{\alpha}\left[x_{t}-k_{t}\right]-\frac{\delta+\rho-\alpha \delta}{\alpha}\left[c_{t}-k_{t}\right], \\
x_{t} & =\mu\left[\alpha k_{t}+(1-\alpha) n_{t}\right],
\end{aligned}
$$

where the lower-cased variable $x_{t}$ denotes the log-deviations of the upper-cased variable $X_{t}$ from steady state (i.e., $\left.x_{t}=\log X_{t} / X\right)$ and we have evaluated the ratios $X / K$ and $C / K$ at the steady state.

It is straightforward to show that this linearized system of equations from the BF model are identical to those implied by equations (39) to (43) in our model.

The mapping between our model and the BF model suggests that indeterminacy arises in our model under the same conditions as those provided by Benhabib and Farmer (1994). To see this, we follow Benhabib and Farmer (1994) and consider an economy in which the output elasticity of capital in the aggregate production function is less than one (i.e., $\mu \alpha<1$ ). The following proposition summarizes the determinacy conditions.

Proposition V.2. The necessary and sufficient condition for equilibrium indeterminacy in the benchmark economy is given by

$$
(1-\alpha) \mu-1>\chi
$$

Proof. See Appendix A.

The condition for indeterminacy in (54) suggests that self-fulfilling fluctuations arise if the slope of the effective labor demand curve exceeds the slope of the labor supply curve. Figure 1 illustrates the labor market adjustment to a shift in expectations of future wealth in the absence of fundamental shocks, where we assume that the 
labor supply curve is flat or, equivalently, labor supply is indivisible (Hansen, 1985; Rogerson, 1988). If agents expect future equity value to rise, the anticipated wealth effect shifts the labor supply curve upward. In the standard RBC model, the labor demand curve is downward sloping so that the shift in the labor supply curve drives up real wages and lowers equilibrium hours and income. Thus, the initial expectations of a rise in equity value would be invalidated. However, in an economy with a sufficiently large $\mu$ (stemming either from increasing returns as in BF or from financial friction as in our model), the effective labor demand curve becomes upward-sloping and is steeper than the labor supply curve (i.e., the condition in equation (54) is satisfied). As shown in the top panel of the figure, an upward shift in the labor supply curve from the wealth effect would raise equilibrium hours. Thus, production increases and the initial expectations of a rise in wealth become self-fulfilling.

Although aggregate dynamics in our model are isomorphic to the BF model, the sources of indeterminacy are quite different. Unlike the BF model in which indeterminacy arises directly from increasing returns technology, our model contains a different mechanism that has to do with financial friction. In particular, all firms have access to a constant returns technology and only productive firms operate. Since operating firms face binding credit constraints, labor demand at the firm level is a function of available credit. For any given level of credit, the labor demand curve is downward sloping. Yet, if agents expect a rise in future equity value, available credit expands and the labor demand curve shifts out. As shown in the bottom panel of Figure 1, although the wealth effect from the anticipated increase in equity value shifts the labor supply curve up and leads to a rise in the real wage, the expansion in available credit shifts the labor demand curve out and, with a sufficiently large financial multiplier (i.e., a sufficiently large $\mu$ ), it can lead to a rise in equilibrium hours. A rise in hours would confirm the initial expectations and lead to self-fulfilling equilibria. Therefore, multiple equilibria in our model stem from financial friction, not from increasing returns.

V.3. Variable capacity utilization. In an important study, Wen (1998) shows that incorporating variable capacity utilization in the BF model helps to lower substantially the required degree of increasing returns to generate multiple equilibria. We now extend our model to allow for variable capacity utilization and show that the model's aggregate dynamics are observationally equivalent to those in the Wen model.

Following Wen (1998), we assume that increases in the capacity utilization rate accelerate capital depreciation. In particular, we assume that the household's budget 
constraint (4) is replaced by

$$
C_{t}^{h}+K_{t+1} \leq w_{t} N_{t}+\left[1+r_{t} u_{t}-\delta\left(u_{t}\right)\right] K_{t}, \quad \forall t \geq 0
$$

where $u_{t}$ denotes the capacity utilization. As in the benchmark model, all capital accumulation is done by the household. The capital depreciation rate varies with capacity utilization according to

$$
\delta\left(u_{t}\right)=\delta_{0} \frac{u_{t}^{1+\eta}}{1+\eta}
$$

where $\delta_{0} \in(0,1)$ is a constant and $\eta>0$ measures the elasticity of the depreciation rate with respect to capacity utilization. The household's optimizing choices now include an additional endogenous variable - the capacity utilization rate $u_{t}$.

With variable capacity, the aggregate production function (37) becomes

$$
Y_{t}=\frac{\sigma}{\sigma-1}\left[\frac{\tilde{\beta} \theta}{1-\tilde{\beta}}\left(\frac{1}{\sigma} Y_{t}-\phi\right)-\phi\right]^{\frac{1}{\sigma+1}}\left(A_{t}\left(u_{t} K_{t}\right)^{\alpha} N_{t}^{1-\alpha}\right)^{\frac{\sigma}{\sigma+1}} .
$$

Here, unlike in the benchmark model, the quantity produced depends on the effective capital services $u_{t} K_{t}$ rather than the physical units of capital $K_{t}$.

We first note that introducing variable capacity utilization raises the magnitude of the financial multiplier. In particular, we have

Proposition V.3. In the extended model with variable capacity utilization, a 1 percent change in TFP holding input factors constant results in $\tilde{\mu}>1$ percent change in aggregate output, where

$$
\tilde{\mu} \equiv \frac{d \log Y_{t}}{d \log A_{t}}=\frac{\mu(1+\eta)}{1+\eta-\alpha \mu}>\mu
$$

where $\mu$ is the financial multiplier in the benchmark model and is given by equation (36).

Proof. See Appendix B.2.

Accordingly, introducing variable capacity utilization makes indeterminacy more likely, as in Wen's model. In particular, we show that

Proposition V.4. The extended model with variable capacity utilization has aggregate dynamics equivalent to those in the representative agent model studied by Wen (1998), where the social planner solves the problem

$$
\operatorname{Max} \quad U=\int e^{-\rho t}\left[\log C_{t}-a_{L} \frac{N_{t}^{1+\chi}}{1+\chi}\right]
$$


subject to

$$
C_{t}+\dot{K}_{t}=\left(u_{t} K_{t}\right)^{\alpha} N_{t}^{1-\alpha}\left[\left(u_{t} \bar{K}_{t}\right)^{\alpha} \bar{N}_{t}^{1-\alpha}\right]^{\mu-1}-\delta_{t} K_{t},
$$

where $\delta_{t}=\delta_{0} \frac{u_{t}^{1+\eta}}{1+\eta}$.

Proof. See Appendix B.4.

The conditions for indeterminacy are summarized in the following proposition:

Proposition V.5. The necessary and sufficient condition for equilibrium indeterminacy in the extended model with capacity utilization is given by

$$
(1-\alpha) \tilde{\mu}-1>\chi
$$

Proof. The proof is the same as in Proposition V.2, with the financial multiplier $\mu$ replaced by $\tilde{\mu}$.

Since $\tilde{\mu}>\mu$, the indeterminacy conditions in (54) and (61) reveal that incorporating variable capacity utilization makes multiple equilibria more likely. This result is analogous to that obtained by Wen (1998) in a representative agent economy with increasing returns, although in the context of financial friction.

V.4. Empirical plausibility of self-fulfilling equilibria. We have established that, to a first-order approximation, the model with financial friction is observationally equivalent to a representative-agent economy with aggregate increasing returns. We have shown that it is possible, at least in theory, to generate multiple equilibria in our model, provided that the financial multiplier is sufficiently large. We now examine the empirical plausibility of self-fulfilling business cycles in the model under calibrated parameters.

The parameters to be calibrated include the subjective discount factors $\beta$ for the household and $\tilde{\beta}$ for the entrepreneur, the capital depreciation rate $\delta$, the capital income share $\alpha$, the inverse Frisch elasticity of labor supply $\chi$, the elasticity $\eta$ of depreciation with respect to capacity utilization rate, the scale parameter of the Pareto distribution for the idiosyncratic productivity shocks $\sigma$, the parameter measuring the strength of contract enforcement $\theta$, and the steady-state ratio of fixed cost of financial intermediation to aggregate output $\bar{\phi}$. Table 1 summarizes the calibrated parameter values.

We set $\beta=0.99$, implying an annual risk-free interest rate of 4 percent. We set $\delta=0.025$, corresponding to an annual capital depreciation rate of 10 percent. We set $\alpha=0.3$ to match the labor income share of 70 percent in the U.S. data. We assume 
that labor is indivisible (Hansen, 1985; Rogerson, 1988), which implies that $\chi=0$. We follow Wen (1998) and set $\eta=0.4$.

The remaining parameters are those related to financial friction. In the model, the difference between $\tilde{\beta}$ and $\beta$ reflects the risk of business failure. We set $\tilde{\beta}=0.98$, implying a business failure rate of about 1 percent at the quarterly frequency, in line with the estimate obtained by Fisher (1999). We set $\sigma=6$, which implies a markup of 20 percent for operating firms. We set $\bar{\phi}=0.06$, which corresponds to the average value-added share of finance and insurance industry from 1960 to 2010 in the United States. Given $\tilde{\beta}, \sigma$, and $\bar{\phi}$, we $\theta=0.41$ so that the model implies a steady-state ratio of private credit to quarterly GDP of 2.08 , as in the U.S. data. ${ }^{7}$

These calibrated parameters imply a financial multiplier of $\mu=1.11$ in the benchmark model and $\tilde{\mu}=1.51$ in the extended model with variable capacity utilization. The size of the financial multiplier $\mu$ implies that, under the calibrated labor share and Frisch elasticity of labor supply, the condition (54) for multiple equilibria is not satisfied and thus the benchmark model has a unique local equilibrium. However, the size of $\tilde{\mu}$ in the extended model with capacity utilization does meet the condition (B38) and thus the model can generate sunspot-driven equilibria.

V.5. The role of financial friction parameters. To isolate the importance of the financial friction parameters $\theta$ and $\phi$ in generating multiple equilibria in the model with variable capacity utilization, we fix all the other parameters at their calibrated values and examine the combinations of $\theta$ and $\phi$ that lead to multiplicity of equilibria. We focus on admissible values of $\theta$ and $\phi$ so that the model has an interior solution. We derive the parameter restrictions in Appendix B.5.

Figure 2 plots the admissible region and indeterminacy region in the space of $\theta$ and $\tilde{\phi}^{8}$ The figure shows that there is a large set of combinations of financial friction parameters that leads to multiple equilibria. For any given value of $\theta$, a large enough $\phi$ leads to multiplicity; for any given value of $\phi$, a large enough $\theta$ leads to multiplicity. The figure also shows that the fixed cost of financial intermediation is crucial for

\footnotetext{
${ }^{7}$ We measure nominal private credit by the non-farm, nonfinancial business liabilities based on credit market instruments. The data are taken from the Flow of Funds Tables of the Federal Reserve through Haver Analytics (private credit is the sum of OL10TCR5@FFUNDS and OL11TCR5@FFUNDS). The sample mean of the ratios of nominal private credit to annualized nominal GDP is about 0.52 for the period from 1960:Q1 to 2011:Q1, implying a quarterly average of 2.08 .

${ }^{8}$ One could easily transform $\tilde{\phi}$ into $\phi$ using the relation in (40) and plot the parameter regions in the space of $(\phi, \theta)$.
} 
indeterminacy. If $\phi$ is close to zero, then the model has a unique equilibrium for all admissible values of $\theta$. Multiple equilibria can be obtained only for large enough values of $\phi$.

\section{CONClusion}

We have studied the possibility of self-fulfilling, sunspot-driven fluctuations in an economy with credit constraints. We find that financial friction in this economy leads to misallocation of resources since productive firms face binding credit constraints. Interactions between firms' equity value and credit limits under credit constraints generate a financial multiplier that amplifies the effects of fundamental shocks on macroeconomic fluctuations. The financial multiplier stems from a credit externality. At the aggregate level, the credit externality manifests in the form of increasing returns and can lead to multiple local equilibria under plausible parameter values. Our finding suggests that an economy with poor contract enforcement and high cost of credit-market access suffers not just from lower TFP, it is also more likely to suffer from aggregate instability as the economy is prone to sunspot-driven business cycle fluctuations. 


\section{Appendix A. Proof of Proposition V.2}

In Proposition V.2, we establish the condition for indeterminacy in the benchmark model. We now provide a formal proof.

Proof. We reduce the system of log-linearized equilibrium conditions (50) to (53) into two equations in $k$ and $c$ and show that both roots of the Jacobian are negative under the condition in (54).

Since the reduced system has one state variable, indeterminacy occurs if and only if both eigenvalues of the Jacobian matrix are negative. The Jacobian evaluated at the steady state is

$$
J=\left[\begin{array}{cc}
\frac{(\rho+\delta)}{\alpha} \Omega_{1}+\frac{(\rho+\delta)}{\alpha}-\delta & \frac{(\rho+\delta)}{\alpha} \Omega_{2}-\frac{(\rho+\delta)}{\alpha}+\delta \\
(\rho+\delta) \Omega_{1} & (\rho+\delta) \Omega_{2}
\end{array}\right]
$$

where $\Omega_{1}=\frac{(\mu \alpha-1)(1+\chi)+\mu(1-\alpha)}{1+\chi-\mu(1-\alpha)}$ and $\Omega_{2}=-\frac{\mu(1-\alpha)}{1+\chi-\mu(1-\alpha)}$.

Denote by $\lambda_{1}$ and $\lambda_{2}$ the eigenvalues of $J$. Then the necessary and sufficient conditions for indeterminacy are

$$
\operatorname{det}(J)=\lambda_{1} \lambda_{2}>0, \quad \operatorname{Trace}(J)=\lambda_{1}+\lambda_{2}<0 .
$$

The determinant of $J$ is given by

$$
\operatorname{det}(J)=(\rho+\delta)\left[\frac{(\rho+\delta)}{\alpha}-\delta\right] \frac{(1-\mu \alpha)(1+\chi)}{\mu(1-\alpha)-(1+\chi)}
$$

Since the economy that we consider has $\mu \alpha<1$, we have $\operatorname{det}(J)<0$ if the inequality (54) holds (i.e., if $(1-\alpha) \mu-1>\chi)$.

Indeterminacy also requires $\operatorname{Trace}(J)<0$. The trace of $J$ is given by

$$
\begin{aligned}
\operatorname{Trace}(J) & =\frac{(\rho+\delta)}{\alpha} \Omega_{1}+\frac{(\rho+\delta)}{\alpha}-\delta+(\rho+\delta) \Omega_{2} \\
& =\frac{(\rho+\delta) \mu}{1+\chi-\mu(1-\alpha)}(\chi+\alpha)-\delta
\end{aligned}
$$

Clearly, if $(1-\alpha) \mu-1>\chi$, then $\operatorname{Trace}(J)<0$.

\section{Appendix B. The Model With VARIABle CAPACity Utilization}

We now describe the model with variable capacity utilization. To help exposition, we follow Wen (1998) by assuming that the household decides the capacity utilization rate. Since the entrepreneur is less patient, only the household holds capital in equilibrium. In this Appendix, we derive the optimizing conditions that characterize the aggregate dynamics. We prove Propositions V.3 and V.4. Finally, we derive 
the admissible set of financial-friction parameters $(\phi, \theta)$ as well as the indeterminacy region.

B.1. Optimizing conditions and aggregate dynamics. The household maximizes the utility

$$
E_{0} \sum_{t=0}^{\infty} \beta^{t}\left[\log \left(C_{t}^{h}\right)-a_{L} \frac{N_{t}^{1+\chi}}{1+\chi}\right]
$$

subject to the budget constraint

$$
C_{t}^{h}+K_{t+1} \leq\left[1+r_{t} u_{t}-\delta\left(u_{t}\right)\right] K_{t}+w_{t} N_{t}
$$

The term $u_{t}$ denotes the fraction of capital stock that the household rents out to the firms. Heavier capacity utilization accelerates capital depreciation. The depreciation function is given by

$$
\delta\left(u_{t}\right)=\delta_{0} \frac{u_{t}^{1+\eta}}{1+\eta}
$$

where $\eta>0$.

The household's optimizing choices of capital stock, the utilization rate, and labor supply lead to the first-order conditions

$$
\begin{aligned}
\frac{1}{C_{t}^{h}} & =\beta E_{t} \frac{1}{C_{t+1}^{h}}\left[1+r_{t+1} u_{t+1}-\delta\left(u_{t+1}\right)\right], \\
r_{t} & =\delta_{0} u_{t}^{\eta}, \\
\frac{1}{C_{t}^{h}} w_{t} & =a_{L} N_{t}^{\chi} .
\end{aligned}
$$

Using the depreciation function (B3) and the optimizing condition for the utilization rate (B5), we can rewrite the capital Euler equation (B4) as

$$
\frac{1}{C_{t}^{h}}=\beta E_{t} \frac{1}{C_{t+1}^{h}}\left[1+\frac{\eta}{1+\eta} r_{t+1} u_{t+1}\right] .
$$

The financial contracts are the same as in the benchmark model. The factor market clearing conditions now need to take into account of the utilization rate and become

$$
\int k_{t}(\omega) f(\omega) d \omega=u_{t} K_{t}, \quad \int n_{t}(\omega) f(\omega) d \omega=N_{t} .
$$

The goods market clearing condition is the same as in the benchmark model:

$$
C_{t}^{h}+K_{t+1}+C_{t}^{e}=\left(1-\delta_{t}\right) K_{t}+Y_{t}-\phi
$$

where $Y_{t}$ denotes aggregate output and is given by

$$
Y_{t}=\frac{\sigma}{\sigma-1}\left[\frac{\tilde{\beta} \theta}{1-\tilde{\beta}}\left(\frac{1}{\sigma} Y_{t}-\phi\right)-\phi\right]^{\frac{1}{\sigma+1}}\left(A_{t} u_{t}^{\alpha} K_{t}^{\alpha} N_{t}^{1-\alpha}\right)^{\frac{\sigma}{\sigma+1}}
$$


and $C_{t}^{e}$ denotes aggregate dividend (or the entrepreneur's consumption) and is related to aggregate output by

$$
C_{t}^{e}=\frac{1}{\sigma} Y_{t}-\phi
$$

Aggregating the firms' cost-minimizing conditions results in

$$
w_{t} N_{t}=(1-\alpha) \varphi_{t} A_{t} u_{t}^{\alpha} K_{t}^{\alpha} N_{t}^{1-\alpha}=(1-\alpha) \frac{\sigma-1}{\sigma} Y_{t},
$$

and

$$
r_{t} u_{t} K_{t}=\alpha \varphi_{t} A_{t} u_{t}^{\alpha} K_{t}^{\alpha} N_{t}^{1-\alpha}=\alpha \frac{\sigma-1}{\sigma} Y_{t} .
$$

Using (B12) and (B13), we rewrite the household's optimizing conditions as

$$
\begin{gathered}
\frac{1}{C_{t}^{h}}(1-\alpha) \frac{\sigma-1}{\sigma} \frac{Y_{t}}{N_{t}}=a_{L} N_{t}^{\chi}, \\
\frac{1}{C_{t}^{h}}=\beta E_{t} \frac{1}{C_{t+1}}\left[1+\alpha \frac{\eta}{1+\eta} \frac{\sigma-1}{\sigma} \frac{Y_{t+1}}{K_{t+1}}\right] .
\end{gathered}
$$

Aggregate dynamics in the model with variable capacity utilization are fully characterized by the following system of equations:

$$
\begin{aligned}
X_{t} & =\left[\frac{\tilde{\beta} \theta}{1-\tilde{\beta}}\left(\frac{1}{\sigma-1} X_{t}-\tilde{\phi}\right)\right]^{\frac{1}{\sigma+1}}\left(A_{t} u_{t}^{\alpha} K_{t}^{\alpha} N_{t}^{1-\alpha}\right)^{\frac{\sigma}{\sigma+1}} \\
X_{t} & =C_{t}^{h}+K_{t+1}-\left(1-\delta_{t}\right) K_{t} \\
\frac{1}{C_{t}^{h}}(1-\alpha) \frac{X_{t}}{N_{t}} & =a_{L} N_{t}^{\chi} \\
\frac{1}{C_{t}^{h}} & =\beta E_{t} \frac{1}{C_{t+1}^{h}}\left[1-\delta_{t+1}+\alpha \frac{X_{t+1}}{K_{t+1}}\right] \\
\alpha \frac{X_{t}}{K_{t}} & =\delta_{0} u_{t}^{\eta+1}
\end{aligned}
$$

where $X_{t} \equiv \frac{\sigma-1}{\sigma} Y_{t}$ and $\tilde{\phi}=\frac{\tilde{\beta} \theta+1-\tilde{\beta}}{\tilde{\beta} \theta} \phi$.

B.2. Proof of Proposition V.3. We are now ready to derive the financial multiplier in the model with variable capacity utilization as stated in Proposition V.3 in the text.

Proof. Log-linearizing the aggregate production function (B16) around the deterministic steady state, we obtain

$$
\hat{X}_{t}=\left(\alpha \hat{u}_{t}+\alpha \hat{K}_{t}+(1-\alpha) \hat{N}_{t}+\hat{A}_{t}\right) \frac{\sigma}{\sigma+1-\xi} .
$$

Using the log-linearized version of the optimizing conditions for the utilization rate in (B20), we substitute out $\hat{u}_{t}$ and obtain

$$
\hat{X}_{t}=\tilde{\mu} \hat{A}_{t}+\tilde{\mu} \alpha \frac{\eta}{1+\eta} \hat{K}_{t}+\tilde{\mu}(1-\alpha) \hat{N}_{t},
$$


where $\tilde{\mu} \equiv \frac{\mu(1+\eta)}{1+\eta-\alpha \mu}>\mu$, with $\mu$ being the financial multiplier in the benchmark model. Thus, holding input factors constant, a 1 percent change in TFP leads to a $\tilde{\mu}$ percent change in aggregate output.

B.3. Aggregate dynamics in continuous time. As in the benchmark model, we use a continuous-time version of the model to examine the possibility of indeterminacy in the presence of variable capacity utilization. The system of equations are

$$
\begin{gathered}
X_{t}=\left[\frac{\tilde{\beta} \theta}{1-\tilde{\beta}}\left(\frac{1}{\sigma-1} X_{t}-\tilde{\phi}\right)\right]^{\frac{1}{\sigma+1}}\left(A_{t} u_{t}^{\alpha} K_{t}^{\alpha} N_{t}^{1-\alpha}\right)^{\frac{\sigma}{\sigma+1}} \\
\frac{\dot{K}_{t}}{K_{t}}=\frac{X_{t}}{K_{t}}-\delta_{t}-\frac{C_{t}^{h}}{K_{t}}=\frac{\eta+1-\alpha}{\eta+1} \frac{X_{t}}{K_{t}}-\frac{C_{t}^{h}}{K_{t}} \\
\frac{1}{C_{t}^{h}}(1-\alpha) \frac{X_{t}}{N_{t}}=a_{L} N_{t}^{\chi} \\
\frac{\dot{C}_{t}^{h}}{C_{t}^{h}}=\alpha \frac{X_{t}}{K_{t}}-\delta_{t}-\rho=\alpha \frac{\eta}{\eta+1} \frac{X_{t}}{K_{t}}-\rho, \\
\alpha \frac{X_{t}}{K_{t}}=\delta_{0} u_{t}^{\eta+1}
\end{gathered}
$$

In the steady state, we have

$$
\frac{X}{K}=\frac{\rho(\eta+1)}{\alpha \eta}, \quad \frac{C^{h}}{K}=\frac{(\eta+1-\alpha) \rho}{\alpha \eta} .
$$

Log-linearizing the equilibrium conditions around the steady state, we obtain

$$
\begin{gathered}
x_{t}=\frac{\alpha \eta \mu}{1+\eta-\alpha \mu} k_{t}+\frac{(1-\alpha)(1+\eta) \mu}{1+\eta-\alpha \mu} n_{t}, \\
\dot{k}_{t}=\frac{\rho(\eta+1-\alpha)}{\alpha \eta}\left[x_{t}-k_{t}\right]-\frac{\rho(\eta+1-\alpha)}{\alpha \eta}\left[c_{t}^{h}-k_{t}\right], \\
\dot{c}_{t}^{h}=\rho\left(x_{t}-k_{t}\right), \\
n_{t}(1+\chi)=x_{t}-c_{t}^{h} .
\end{gathered}
$$


B.4. Proof of Proposition V.4. With these log-linearized equilibrium conditions, it is easy to prove the equivalence results stated in Proposition V.4 in the text.

Proof. Denote by $X_{t}=A_{0} u_{t}^{\alpha} K_{t}^{\alpha} N_{t}^{1-\alpha}\left(\bar{u}_{t}^{\alpha} \bar{K}_{t}^{\alpha} \bar{N}_{t}^{1-\alpha}\right)^{\frac{\xi-1}{(\sigma+1-\xi)}}$ aggregate output in Wen's model. The first-order conditions in Wen (1998) are identical to (B24)-(B26) in our model and the resource constraint in his model is also the same as in ours (B23). The log-linearized production function in Wen's model is

$$
x_{t}=\frac{\alpha \eta \mu}{1+\eta-\alpha \mu} k_{t}+\frac{(1-\alpha)(1+\eta) \mu}{1+\eta-\alpha \mu} n_{t},
$$

which is identical to the linearized aggregate production function (B28) in our model.

B.5. Parameter restrictions and the indeterminacy region. We now derive the restrictions on the financial friction parameters $\theta$ and $\tilde{\phi}$ that permit interior solutions, that is, the admissible region. We also derive the combinations of these parameters in the admissible region that lead to indeterminacy.

B.5.1. Admissible parameters. We begin by deriving the combinations of $(\tilde{\phi}, \theta)$ that permit interior solutions.

In the steady-state equilibrium, (B27) shows that the output-capital ratio $X_{k} \equiv$ $\frac{X}{K}$ and the consumption-capital ratio $C_{k} \equiv \frac{C^{h}}{K}$ are independent of financial friction parameters. It follows from the labor supply decision (B24) and the optimal capacity utilization decision (B26) that the steady-state levels of employment $N$ and utilization $u$ are also independent of the financial friction parameters. Without loss of generality, we normalize the steady-state level of technology $A$ such that $A u^{\alpha} N^{1-\alpha}=1$. The aggregate production function (B22) then implies that, in the steady state,

$$
X=\left[\frac{\tilde{\beta} \theta}{1-\tilde{\beta}}\left(\frac{1}{\sigma-1} X-\tilde{\phi}\right)\right]^{\frac{1}{\sigma+1}}\left(K^{\alpha}\right)^{\frac{\sigma}{\sigma+1}}
$$

Since aggregate output is given by $X=\omega^{*} A(u K)^{\alpha} N^{1-\alpha}=\omega^{*} K^{\alpha}$, where $\omega^{*} \geq 1$ is the cutoff level of productivity, interior solution requires that

$$
X \geq K^{\alpha} \equiv X_{\min }
$$

The minimum output $X_{\min }$ can be solved in terms of (nonfinancial) parameters using the fact that the output-capital ratio is invariant to financial friction parameters. In particular, $X_{\min }=K^{\alpha}=\left(X_{\min } / X_{k}\right)^{\alpha}$, so that

$$
X_{\min }=X_{k}^{\frac{\alpha}{\alpha-1}} .
$$


The inequality in (B34) puts restrictions on the admissible values of $\tilde{\phi}$ and $\theta$. All else equal, aggregate output decreases with $\tilde{\phi}$ and increases with $\theta$. Taking the constraint in (B34) as given, we first derive the upper bound for $\tilde{\phi}$ by holding $\theta=1$ and then derive the lower bound for $\theta$ as a function of $\tilde{\phi}$. Denote the upper bound for $\tilde{\phi}$ by $\phi^{\max }$. With $\tilde{\phi}=\phi^{\max }$, aggregate output reaches its lowest level $X_{\min }$. Thus, from (B33) with $\theta=1$ imposed, we have

$$
X_{\min }=\left[\frac{\tilde{\beta}}{1-\tilde{\beta}}\left(\frac{1}{\sigma-1} X_{\min }-\tilde{\phi}\right)\right]^{\frac{1}{\sigma+1}}\left(X_{\min }\right)^{\frac{\sigma}{\sigma+1}} .
$$

Rearranging terms, we obtain

$$
\tilde{\phi}^{\max }=\left[\frac{1}{\sigma-1}-\frac{1-\tilde{\beta}}{\tilde{\beta}}\right] X_{k}^{\frac{\alpha}{\alpha-1}} .
$$

We now derive the lower bound of $\theta$ as a function of $\tilde{\phi}$ such that (B34) is satisfied. Denote this lower bound by $\theta_{\min }(\tilde{\phi})$.We use the production function (B33) to solve for $\theta_{\min }(\tilde{\phi})$ by setting $X=X_{\min }$. This procedure yields

$$
\theta_{\min }(\tilde{\phi})=\frac{\frac{1-\tilde{\beta}}{\tilde{\beta}} X_{\min }}{\frac{1}{\sigma-1} X_{\min }-\tilde{\phi}} .
$$

Thus, the set of admissible financial friction parameters are given by

$$
\mathcal{A}=\left\{(\tilde{\phi}, \theta) \mid 0 \leq \tilde{\phi} \leq \phi^{\max }, \theta_{\min }(\tilde{\phi}) \leq \theta \leq 1\right\} .
$$

B.6. Indeterminacy region. We now derive the combinations of $\tilde{\phi}$ and $\theta$ that lead to indeterminacy.

Proposition V.5 establishes that the necessary and sufficient condition for indeterminacy is given by

$$
\tilde{\mu} \geq \frac{1+\chi}{1-\alpha}
$$

where $\tilde{\mu}=\frac{(1+\eta) \mu}{1+\eta-\alpha \mu}$ with $\mu=\frac{\sigma}{\sigma+1-\xi}$ and $\xi=\frac{1}{1-\tilde{\phi}(\sigma-1) / X}$. The indeterminacy condition in (B38) puts restrictions on the parameters $\tilde{\phi}$ and $\theta$. We now derive these restrictions.

Denote by $\tilde{\mu}^{*} \equiv \frac{1+\chi}{1-\alpha}$ the threshold value of $\tilde{\mu}$ such that indeterminacy obtains if $\tilde{\mu} \geq \tilde{\mu}^{*}$. We define the term

$$
\xi^{*} \equiv \sigma+1-\frac{\sigma}{\mu^{*}}
$$

where $\mu^{*} \equiv \frac{(1+\eta) \tilde{\mu}^{*}}{1+\eta+\alpha \tilde{\mu}^{*}}$. Since $\tilde{\mu}$ is a monotone function of $\xi$, we have $\tilde{\mu} \geq \tilde{\mu}^{*}$ if and only if $\xi \geq \xi^{*}$. Thus, from the definition of $\xi$, indeterminacy obtains if and only if

$$
1-\tilde{\phi} \frac{\sigma-1}{X} \leq \frac{1}{\xi^{*}} .
$$


Define the term

$$
X^{*} \equiv \tilde{\phi} \frac{(\sigma-1) \xi^{*}}{\xi^{*}-1} \text {. }
$$

Indeterminacy obtains if and only if $X \leq X^{*}$. Thus, we can solve the maximum value of $\theta$ as a function of $\tilde{\phi}$ such that, for all $\theta$ below this maximum value, we have $X \leq X^{*}$ and indeterminacy obtains. Denote by $\theta^{\max }(\tilde{\phi})$ the upper bound of $\theta$ for the indeterminacy region. At this value of $\theta$, we have $X=X^{*}$. Thus,

$$
X^{*}=\left[\frac{\tilde{\beta} \theta^{\max }(\tilde{\phi})}{1-\tilde{\beta}}\left(\frac{1}{\sigma-1} X^{*}-\tilde{\phi}\right)\right]^{\frac{1}{\sigma+1}}\left(\frac{X^{*}}{X_{k}}\right)^{\frac{\alpha \sigma}{\sigma+1}},
$$

where we have used the equilibrium condition that $K=\frac{X}{X_{k}}$ for all admissible values of $X$. Substituting out $X^{*}$ using (B40) and rearranging terms, we obtain

$$
\theta^{\max }(\tilde{\phi})=\left[\frac{\xi^{*}(\sigma-1)}{\xi^{*}-1} \tilde{\phi}\right]^{\sigma+1-\alpha \sigma} \frac{X_{k}^{\alpha \sigma}}{\frac{1}{\xi^{*}-1} \tilde{\phi}} \frac{1-\tilde{\beta}}{\tilde{\beta}},
$$

where $\xi^{*}$ is given by (B39).

Thus, the region of indeterminacy is summarized by the set

$$
\mathcal{I} \equiv\left\{(\tilde{\phi}, \theta) \mid 0 \leq \tilde{\phi} \leq \phi^{\max }, \theta_{\min }(\tilde{\phi}) \leq \theta \leq \min \left(\theta^{\max }(\tilde{\phi}), 1\right)\right\}
$$




\section{TABLE 1. Calibrated Parameters}

\begin{tabular}{lll} 
Parameter & Description & Value \\
\hline$\beta$ & Household discount factor & 0.99 \\
$\tilde{\beta}$ & Entrepreneur discount factor & 0.98 \\
$\alpha$ & Capital income share & 0.30 \\
$\delta$ & Capital depreciation rate & 0.025 \\
$\eta$ & Utilization elasticity of depreciation & 0.40 \\
$\chi$ & Inverse Frisch elasticity of labor supply & 0 \\
$\sigma$ & Shape parameter of the productivity distribution & 6.00 \\
$\theta$ & Contract enforcement & 0.41 \\
$\bar{\phi}$ & Cost of financial intermediation as a fraction of GDP & 0.06 \\
\hline
\end{tabular}



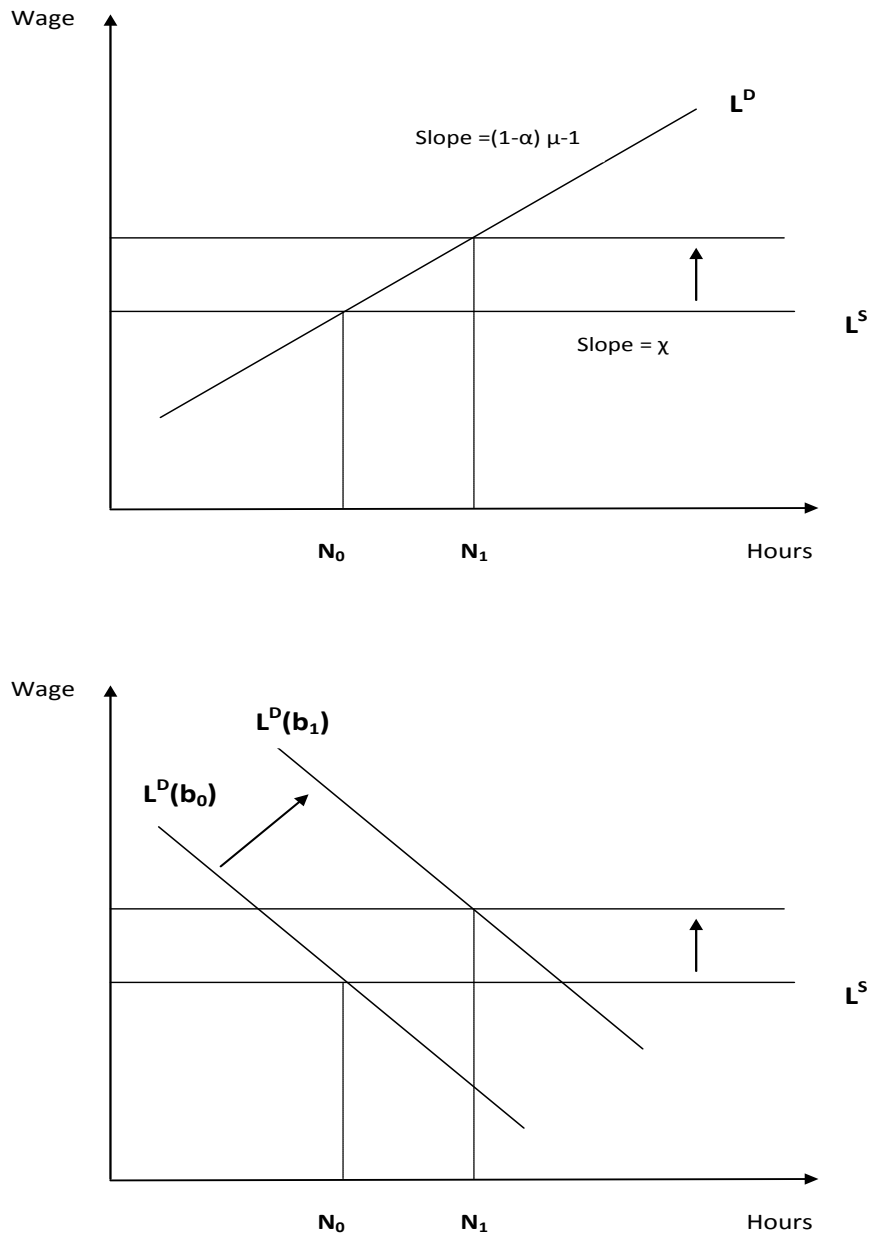

FigURE 1. Labor market adjustment to expectations of increases in wealth under conditions for indeterminacy. Top panel: Aggregate model with increasing returns (Benhabib and Farmer, 1994). Bottom panel: Benchmark model with financial friction. 


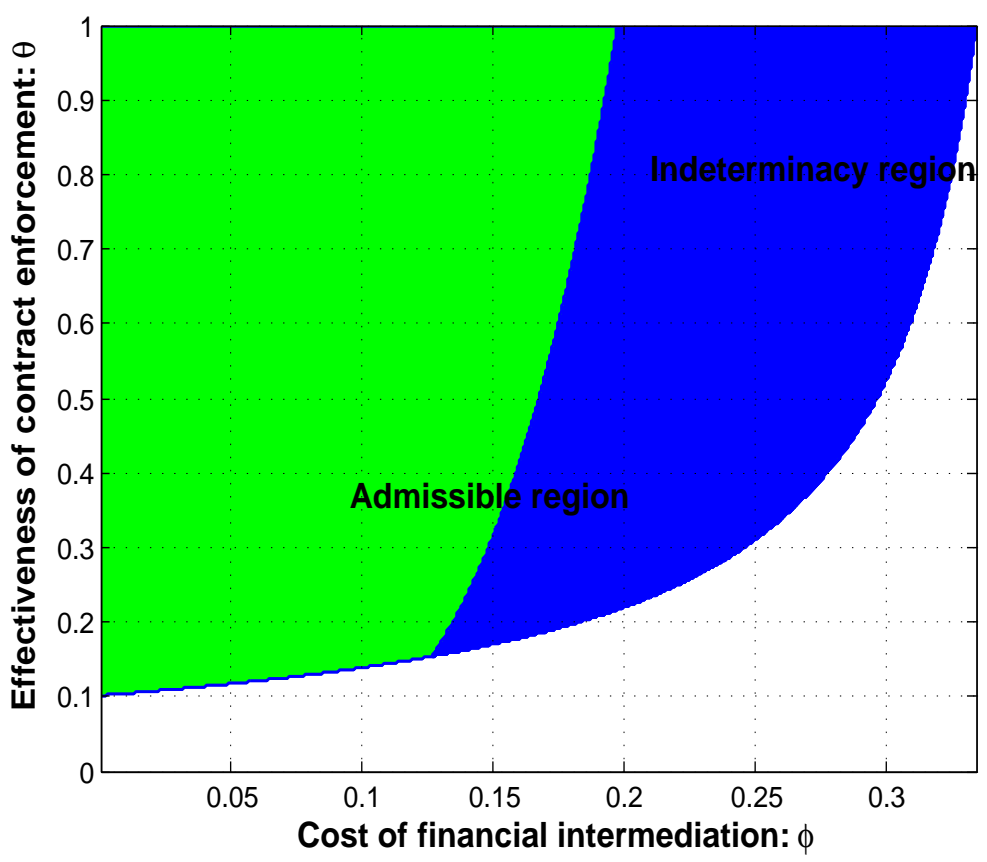

FIGURE 2. Financial friction parameters and indeterminacy in the extended model with variable capacity utilization. The horizontal axis shows the cost of financial intermediation $(\tilde{\phi})$ and the vertical axis shows the strength of contract enforcement $(\theta)$. The admissible region is the sum of the two colored areas. The indeterminacy region is the blue area. 


\section{REFERENCES}

Azariadis, C. (1981): "Self-Fulfilling Prophecies," Journal of Economic Theory, 25, 380-396.

Basu, S., And J. G. Fernald (1995): "Are Apparent Productive Spillovers a Figment of Specification Error?," Journal of Monetary Economics, 36, 165-188.

(1997): "Returns to Scale in U.S. Production: Estimates and Implications," Journal of Political Economy, 105(2), 249-283.

(2001): Why Is Productivity Procyclical? Why Do We Care?pp. 225-302. University of Chicago Press.

BenhabiB, J., And R. E. FARmer (1994): "Indeterminacy and Increasing Returns," Journal of Economic Theory, 63, 19-41.

- (1996): "Indeterminacy and Sector-Specific Externalities," Journal of Monetary Economics, 37, 421-443.

(1999): "Indeterminacy and Sunspots in Macroeconomics," in Handbook of Macroeconomics, ed. by J. B. Taylor, and M. Woodford, vol. 1A, chap. 6, pp. 387448. Elsevier Science, Amsterdam, North-Holland.

Benhabib, J., And K. Nishmura (1998): "Indeterminacy and Sunspots with Constant Returns," Journal of Economic Theory, 81, 58-96.

BenhabiB, J., And Y. WEn (2004): "Indeterminacy, aggregate demand, and the real business cycle," Journal of Monetary Economics, 51, 503-530.

Bernanke, B. S., M. Gertler, and S. Gilchrist (1999): "The Financial Accelerator in a Quantitative Business Cycle Framework," in The Handbook of Macroeconomics, ed. by J. B. Taylor, and M. Woodford, pp. 1341-1393. Elsevier Science B.V., Amsterdam, North Holland.

Carlstrom, C. T., and T. S. Fuerst (1997): "Agency Costs, Net Worth, and Business Fluctuations: A Computable General Equilibrium Analysis," American Economic Review, 87(5), 893-910.

Cass, D., And K. Shell (1983): "Do Sunspots Matter?," Journal of Political Economy, 91, 193-227.

Christiano, L., R. Motto, and M. Rostagno (2008): "Financial Factors in Economic Fluctuations," Manuscript, Northwestern University.

Farmer, R. E., And J.-T. Guo (1994): "Real Business Cycles and the Animal Spirits Hypothesis," Journal of Economic Theory, 63, 42-72.

Fernald, J., AND B. Neiman (2010): "Growth Accounting with Misallocation: Or, Doing Less with More in Singapore," Federal Reserve Bank of San Francisco 
Working Paper 2010-18.

Fisher, J. D. M. (1999): "Credit Market Imperfections and the Heterogeneous Response of Firms to Monetary Shocks," Journal of Money, Credit and Banking, 31(2), $187-211$.

GaLÍ, J. (1994): "Monopolistic competition, business cycles, and the composition of aggregate demand," Journal of Economic Theory, 63, 73-96.

Gertler, M., and N. Kiyotaki (2009): "Financial Intermediation and Credit Policy in Business Cycle Analysis," Manuscript, Princeton University.

Hansen, G. D. (1985): "Indivisible Labor and the Business Cycle," Journal of Monetary Economics, 16, 309-337.

Hsieh, C.-T., And P. J. Klenow (2009): "Misallocation and Manufacturing TFP in China and India," Quarterly Journal of Economics, 124(4), 1403-1448.

JAimoviCH, N. (2007): "Firm dynamics and markup variations: Implications for sunspot equilibria and endogenous economic fluctuations," Journal of Economic Theory, 137, 300-325.

JERMAnn, U., AND V. QuAdRIni (Forthcoming): "Macroeconomic Effects of Financial Shocks," American Economic Review.

Kiyotaki, N., and J. Moore (1997): "Credit Cycles," Journal of Political Economy, $105(2), 211-248$.

- (2008): "Liquidity, Business Cycles, and Monetary Policy," Manuscript, Princeton University and London School of Economics.

LiU, Z., P. Wang, and T. Zha (2011): "Land-Price Dynamics and Macroeconomic Fluctuations," NBER Working Paper No. 17045.

Ramey, G., And V. A. Ramey (1995): "Cross-Country Evidence on the Link Between Volatility and Growth," American Economic Review, 85(5), 1138-1151.

Rogerson, R. (1988): "Indivisible Labor, Lotteries and Equilibrium," Journal of Monetary Economics, 21, 3-16.

Rustuccia, D., And R. Rogerson (2008): "Policy distortions and aggregate productivity with heterogeneous establishments," Review of Economic Dynamics, 11, 707-720.

SchmitT-Grohe, S. (1997): "Comparing Four Models of Aggregate Fluctuations Due to Self-Fulfilling Expectations," Journal of Economic Theory, 72, 96-147.

WANG, P., AND Y. WEN (2008): "Imperfect competition and indeterminacy of aggregate output," Journal of Economic Theory, 143, 519-540. 
Wen, Y. (1998): "Capacity Utilization under Increasing Returns to Scale," Journal of Economic Theory, 81, 7-36.

Woodford, M. (1986): "Stationary Sunspot Equilibria in a Finance Constrained Economy," Journal of Economic Theory, 40, 128-137.

Federal Reserve Bank of San Francisco, Hong Kong University of Science and TECHNOLOGY 